\title{
Foreword to the special issue: regional earth system modeling
}

\author{
Zong-Liang Yang
}

Received: 10 February 2015 / Accepted: 18 February 2015 / Published online: 7 March 2015

(C) The Author(s) 2015. This article is published with open access at Springerlink.com

Over the past decade or so, the term "climate system modeling" has been gradually changed to "earth system modeling", which reflects a shift of emphasis on seeking more understanding and modeling of how human activities (e.g. agriculture, urbanization, energy exploration and exploitation, and socio-economics) affect and are affected by climate variability and change. While anthropogenic greenhouse gases and aerosols as a driving force for climatic change and impacts have been a primary focus of study, changes in land use and land cover, especially urbanization and agricultural practice, have received increasing attention. Because most adaptation and many mitigation decisions are made at local and regional scales, regional earth system modeling is an important tool to provide high-resolution regional information necessary for sound science-based decision-making. In recognition of these needs and developments, the first international symposium on regional earth system modeling and analysis was held in Beijing on May 18-22, 2011. This special issue assembles the papers that were presented at the symposium or later solicited to represent a broad range of topics, which are briefly reviewed below.

Regional earth system modeling can benefit from experience gained and lessons learned in regional climate modeling. Most regional climate modeling has been conducted by nesting a high-resolution limited-area climate model within a coarse-resolution global climate model, and this approach is the so-called one-way nesting such that the global model provides lateral boundary conditions for the regional model but the regional dynamics does not feedback to the global model. By reviewing five currently available variable-resolution global climate models (VR-GCMs), McGregor (2013) in this issue provides an attractive alternative to limited-area regional climate models (RCMs). These VR-GCMs are not only able to provide high-quality dynamically- downscaled regional climate simulations, they also overcome the spurious reflections associated with the lateral boundaries in limited-area RCMs and allow beneficial interactions between flow in the fine-resolution and coarser regions. It is well known that

This article is part of a Special Issue on "Regional Earth System Modeling" edited by Zong-Liang Yang and Congbin Fu.

Z.-L. Yang $(\bowtie)$

Center for Integrated Earth System Science, University of Texas at Austin, Austin, TX 78712, USA

e-mail: liang@jsg.utexas.edu

Z.-L. Yang

Key Laboratory of Regional Climate-Environment Research for Temperate East Asia, Institute of Atmospheric Physics, Chinese Academy of Sciences, Beijing, China 
GCMs have biases that can propagate through lateral boundaries and severely affect regional climate simulations. Therefore, bias-correction is always a topic in regional modeling, especially in downscaling future climate change for societal impact assessments. Done et al. (2013) show a successful example of how such bias can be removed in a manner that retains the day-to-day weather, climate variability and change components.

Factors affecting regional climate variability and change include, but are not limited to, remote oceanic influences, local oceanic processes, high-frequency atmospheric variability, and long-lived greenhouse gases. Regional climate models are well suited to differentiating the roles of the above processes in controlling regional climate and high-impact weather. Done et al. (2013) have also documented the importance of domain size, location and resolution in modeling tropical cyclones. Patricola et al. (2013) used a large-domain regional climate model encompassing North America, South America, the Atlantic Ocean, western Europe, and Africa to separate the effects of remote Pacific influences through the western lateral boundary condition (LBC) and local processes related to Atlantic sea surface temperature anomalies on extreme precipitation patterns in the Midwest United States. An innovative feature of this study is that the authors apply a 10-day low-pass filter to the western LBC to quantify the role of interactions between the eddy and timemean flow in modulating extreme flood events. Tian et al. (2014) describe a terrestrial ecological model that is capable of modeling spatial and temporal variability of three fluxes of major greenhouse gases $\left(\mathrm{CO}_{2}, \mathrm{~N}_{2} \mathrm{O}\right.$, and $\left.\mathrm{CH}_{4}\right)$, and they further compare these three gases' combined and separate global warming potentials, using the United States as an example. More work needs to be done to develop such biogeochemical models, evaluate their performance, and implement them in regional earth system models for integrated impact assessments.

Regional earth system modeling should also emphasize characterization of important regional features, development of regional-specific datasets, and development of models that are tailored for regional use. For example, the Chinese government has implemented a series of large-scale reforestation/afforestation policies to address various natural disasters and environmental crises, especially in North China. Have these policies caused the changes of the land surface parameters and climate conditions? In two companion papers, Fan et al. (2014a) provide observational evidence of land use and land cover change (LULCC) over the Loess Plateau region from 2001 to 2009, while Fan et al. (2014b) relate LULCC to climate variations and human activities using statistical analysis. Both studies provide an ideal case for further modeling studies, although relevant component modules remain to be developed and refined. Dan et al. (2013) describe a land surface eco-physiological model and apply it within a regional climate model to study its impact on simulating the summer climate in East China. $\mathrm{Gu}$ et al. (2013) document the importance of a well-calibrated one-dimensional physically based lake model coupled to a regional climate model for lake temperature simulations. Barlage et al. (2015) show that allowing groundwater-soil moisture interaction may improve the simulations of soil moisture, latent heat fluxes, and 2-m air and dew-point temperatures. Wang et al. (2013) describe recent community efforts in China in developing regional climate and environment modeling.

Arguably, the largest rate of urbanization occurred in China during the past decades. Feng et al. (2013) have investigated the impacts of urbanization and anthropogenic heat release in China on the East Asian monsoon using a limited-area regional climate model coupled to an urban canyon model. A different urban canyon model coupled to a land surface model is used by Oleson et al. (2013) to quantify present-day and projected mid-21st century rural and urban heat stress for boreal summer over the U.S. and southern Canada and examine the 
effects of three urban density classes on heat stress. Future work needs better urbanization datasets. One example is provided by Jia et al. (2014) who use multiscale high-resolution satellite data and field campaigns to derive urban fraction and road (street) width, two key parameters in urban modeling, for China. The impacts of these refined and region-specific urbanization datasets in China on regional environment and climate remain to be investigated.

Regional-scale environment-human interaction and their integrated modeling for resource decision-making require new initiatives and new lines of thinking. The resultant models are expected to address sustainability and the food-water-energy-climate nexus. Adam et al. (2014) describe a BioEarth initiative, which integrates multiple stand-alone models (such as atmospheric, terrestrial, aquatic, and economic models) within a modular earth system modeling framework to generate usable information for agricultural and natural resource decisionmaking at the regional scale. Kraucunas et al. (2014) describe another initiative called the Platform for Regional Integrated Modeling and Analysis (PRIMA) initiated at Pacific Northwest National Laboratory (PNNL), and provide an excellent overview of the platform, initial results, and lessons learned.

In summary, regional earth system modeling is a fast emerging and rapidly growing research endeavor. The entire research and stake-holder communities are facing great challenges and opportunities. Challenges exist in understanding physical, chemical, biological, and human processes across multiple spatiotemporal scales and in processing big data from remote sensing, in-situ observations, decision-making, ensemble simulations, and comprehensive modeling output. The papers included in this special issue provide some key examples and pointing to a bright future for growth and application.

Acknowledgments I would like to thank all the contributors to this special issue. This paper was supported by grants from NASA (NNX11AJ43G), the National Natural Science Foundation of China (41375088), and the National Basic Research Program of China (2012CB956203). The symposium was generously sponsored by Key Laboratory of Regional Climate-Environment for East Asia (RCE-TEA), Chinese Academy of Sciences, China, the Jackson School of Geosciences, the University of Texas at Austin, USA, Institute of Climate and Global Change Research, Nanjing University, China, Monsoon Asia Integrated Regional Study (MAIRS), and National Natural Science Foundation of China (NSFC). Finally, I would like to thank Congbin Fu for acting as co-guest editor of this issue.

Open Access This article is distributed under the terms of the Creative Commons Attribution License which permits any use, distribution, and reproduction in any medium, provided the original author(s) and the source are credited.

\section{References}

Adam JC, Stephens JC, Chung SH, Brady MP, Evans RD, Kruger CE, Lamb BK, Liu ML, Stöckle CO, Vaughan JK, Rajagopalan K, Harrison JA, Tague CL, Kalyanaraman A, Chen Y, Guenther A, Leung F-Y, Leung LR, Perleberg AB, Yoder J, Allen E, Sarah Anderson S, Chandrasekharan B, Malek K, Mullis T, Miller C, Nergui T, Poinsatte J, Reyes J, Zhu J, Choate JS, Jiang XY, Nelson R, Yoon J-H, Yorgey GG, Johnson K, Chinnayakanahalli KJ, Hamlet AF, Nijssen B, Walden V (2014) BioEarth: envisioning and developing a new regional earth system model to inform natural and agricultural resource management. Clim Chang. doi: 10.1007/s10584-014-1115-2

Barlage M, Tewari M, Chen F, Miguez-Macho G, Yang Z-L, Niu GY (2015) The effect of groundwater interaction in North American regional climate simulations wit WRF/Noah-MP. Climate Change

Dan L, Cao FQ, Gao R (2013) The improvement of a regional climate model by coupling a land surface model with eco-physiological processes: a case study in 1998. Clim Chang. doi:10.1007/s10584-013-0997-8 
Done JM, Holland GJ, Bruyère CL, Leung LR, Suzuki-Parker A (2013) Modeling high-impact weather and climate lessons from a tropical cycle perspective. Climate Change. doi:10.1007/s10584-013-0954-6

Fan XG, Ma ZG, Yang Q, Han YH, Mahmood R, Zheng ZY (2014a) Land use/land cover changes and regional climate over the loess plateau during 2001-2009. Part I: observational evidence. Clim Chang. doi:10.1007/ s10584-014-1069-4

Fan XG, Ma ZG, Yang Q, Han YH, Mahmood R (2014b) Land use/land cover changes and regional climate over the Loess Plateau during 2001-2009. Part II: interrelationship from observations. Clim Chang. doi:10.1007/ s10584-014-1068-5

Feng JM, Wang YL, Ma ZG (2013) Long-term simulation of large-scale urbanization effect on the East Asian monsoon. Clim Chang. doi:10.1007/s10584-013-0885-2

Gu HP, Jin JM, Wu YH, Ek MB, Subin ZM (2013) Calibration and validation of lake surface temperature simulations with the coupled WRF-lake model. Clim Chang. doi:10.1007/s10584-013-0978-y

Jia GS, Xu RH, Hu YH, He YT (2014) Multi-scale remote sensing estimates of urban fractions and road widths for regional models. Clim Chang. doi:10.1007/s10584-014-1114-3

Kraucunas I, Clarke L, Dirks J, Hathaway J, Hejazi M, Hibbard K, Huang MY, Jin CL, Kintner-Meyer M, van Dam KK, Leung R, Li H-Y, Moss R, Peterson M, Rice J, Scott M, Thomson A, Voisin N, West T (2014) Investigating the nexus of climate, energy, water, and land at decision-relevant scales: the Platform for Regional Integrated Modeling and Analysis (PRIMA). Clim Chang. doi:10.1007/s10584-014-1064-9

McGregor JL (2013) Recent developments in variable-resolution global climate modelling. Clim Chang. doi:10. 1007/s10584-013-0866-5

Oleson KW, Monaghan A, Wilhelmi O, Barlage M, Brunsell N, Feddema J, Hu L, Steinhoff DF (2013) Interactions between urbanization, heat stress, and climate change. Clim Chang. doi:10.1007/s10584-0130936-8

Patricola CM, Chang P, Saravanan R (2013) Impact of Atlantic SST and high frequency atmospheric variability on the 1993 and 2008 Midwest floods: regional climate model simulations of extreme climate events. Clim Chang. doi:10.1007/s10584-013-0886-1

Tian HQ, Chen GS, Lu CQ, Xu XF, Hayes DJ, Ren W, Pan SF, Huntzinger DN, Wofsy SC (2014) North American terrestrial $\mathrm{CO} 2$ uptake largely offset by $\mathrm{CH} 4$ and $\mathrm{N} 2 \mathrm{O}$ emissions: toward a full accounting of the greenhouse gas budget. Clim Chang. doi:10.1007/s10584-014-1072-9

Wang SY, Fu CB, Wei HL, Qian Y, Xiong Z, Feng JM, Zhao DM, Dan L, Han ZW, Su BK, Zhao M, Zhang YC, Tang JP, Liu HN, Wu J, Zeng XM, Chen M, Wang LZ (2013) Regional integrated environmental modeling system: development and application. Clim Chang. doi:10.1007/s10584-013-0973-3 